\title{
Experimental Study on RC Beams Strengthened by 3D Textile Fabric
}

\author{
Dohyeong Kim ${ }^{1}$, Sung Jig Kim ${ }^{1}$, Chunho Chang ${ }^{2}$, and Jong Hee $\mathrm{An}^{3}$
}

\begin{abstract}
The paper introduces the experimental program of investigation on the performance of $\mathrm{RC}$ beams strengthened with Ultra-High-Molecular-Weight Polyethylene (UHMWPE) fabric. A research program aims at developing 3D UHMWPE textile fabric to improve the structural performance of $\mathrm{RC}$ members. A total of six of specimens is constructed and experimentally investigated through static tests in order to assess the structural behavior of the RC beams strengthened by 3D UHMWPE textile fabric. The first set of specimens was a normal beam without any retrofit. The second set of specimens was strengthened by 3D UHMWPE textile fabric. Testing data were analyzed to investigate the performance of the specimens retrofitted or strengthened with UHMWPE fiber compared to the non-retrofitted $\mathrm{RC}$ beam responses.
\end{abstract}

Keywords - UHMWPE, Textile fabric, Retrofit, RC Beam

\section{Introduction}

Many of recent researches to improve the performance of existing or new structures subjected to the extreme loads such as earthquakes have focused on the structural retrofitting method by modifying structures and structural components or adding additional elements. Retrofitting strategies that address structural deficiencies often aim to enhance the confinement or flexural strength for concrete members in order to provide an increased ductility capacity retrofitting methods include steel jacketing and steel plates wrapped around the concrete members.

FRP materials are widely used for a retrofitting or repair technology due to their light-weight, high strength, and high stiffness. Thus, the use of fiber composite materials in seismic retrofit applications to structural members has grown rapidly since the 1990 s due to its effectiveness in strengthening the structural members of existing buildings which cannot satisfy current design demands [1 5].

\footnotetext{
${ }^{1}$ Dohyeong Kim (Graduate Student), Sung Jig Kim (Assistant Professor) Department of Architectural Engineering, Keimyung University South Korea
} and/or improved shear strength. Some examples of such or fiber (carbon or glass) reinforced plastic (FRP) sheets

Compared to the steel plate bonding method, the FRP strengthening method has advantages such as easy installation due to the light weight, chemical resistance and lower labor cost. For instance, the Carbon Fiber Reinforced Polymer (CFRP) retrofit method enhances both stiffness/strength and ductility of structural members due to the high strength and stiffness of CFRP materials [6]. However, most of current studies on the application of FRP materials to civil structures are limited to either the retrofitting or repair technology of the existing structures.

More recently, a relatively new composite material, textile reinforced concrete (TRC) has been developed. TRC composite comprises a combination of multiaxial fabrics (3D) and a fine-grained cementitious matrix. Recent studies indicate that this TRC composite can significantly improve tensile strength, ductility, and energy absorption properties compared with conventional, normal concrete [7-9]. However, previous researches have focused on composites members without conventional steel reinforcement and thus, the application of $3 \mathrm{D}$ fabric to the conventional reinforced concrete structures has not been studied yet.

In this paper RC beams strengthened by 3D UHMWPE textile fabric were constructed and tested to investigate the effect 3D fabric on RC beams. A total of six specimens were constructed and tested in order to assess the structural behavior of the retrofitted RC beams. The first set of specimens was a normal beam without any retrofit. The second set of specimens was strengthened by 3D UHMWPE textile fabric.

\section{Experimental Program}

\section{A. UHMWPE 3D Textile Fabric}

Ultra-High-Molecular-Weight Polyethylene (UHMWPE) fabric is used in this study. UHMWPE has been used in various areas. For example, UHMWPE has been considered as a successful biomaterial for use in hip, knee, and spine implants over 40years. Also, UHMWPE fibers are used in armor, in particular, personal armor and on occasion as vehicle armor.

TABLE I. MATERIAL CHARACTERISTICS OF FIBERS

Chunho Chang, Associate Professor
Department of Civil Engineering, Keimyung University South Korea

${ }^{3}$ Jong Hee An, Associate Professor

Engineering Department, Daegu Metropolitan City South Korea

\begin{tabular}{|c|c|c|c|c|}
\hline Type & $\begin{array}{c}\text { Tensile } \\
\text { Strength } \\
(\mathbf{M P a})\end{array}$ & $\begin{array}{c}\text { Elastic } \\
\text { Modulus } \\
(\mathbf{M P a})\end{array}$ & $\begin{array}{c}\text { Elongation } \\
(\mathbf{\%})\end{array}$ & $\begin{array}{c}\text { Density } \\
\left(\mathbf{g} / \mathbf{c m}^{3}\right)\end{array}$ \\
\hline UHMWPE & 3500 & $1.10 \times 10^{6}$ & 3.5 & 0.97 \\
\hline Carbon Fiber & 3500 & $2.30 \times 10^{6}$ & $0.2 \sim 2.4$ & 1.97 \\
\hline Aramid Fiber & 2800 & $1.09 \times 10^{6}$ & $2.4 \sim 4.4$ & 1.45 \\
\hline
\end{tabular}


As shown in Table I, the tensile strength of UHMWPE is similar to that of Carbon fiber while the elastic modulus of UHMWPE is close to that of Aramid fiber. Compared to other fibers, UHMWPE has high elongation and low density. Thus, due to these material characteristics, some of recent researches on seismic retrofitting method have focused on application of UHMWPE to civil structures [10].

In this study, a new 3D fabric using UHMWPE fiber was developed to improve the structural behavior of $\mathrm{RC}$ members as shown in Fig. 1. Top and bottom layers are UHMWPE fiber with the grid of $35 \mathrm{~mm} \times 40 \mathrm{~mm}$. The spacers are implemented between two UHMWPE layers and its length is about $20 \mathrm{~mm}$. This 3D UHMWPE fiber is located at the bottom of $\mathrm{RC}$ beam and thus its flexural behavior is expected to be improved.
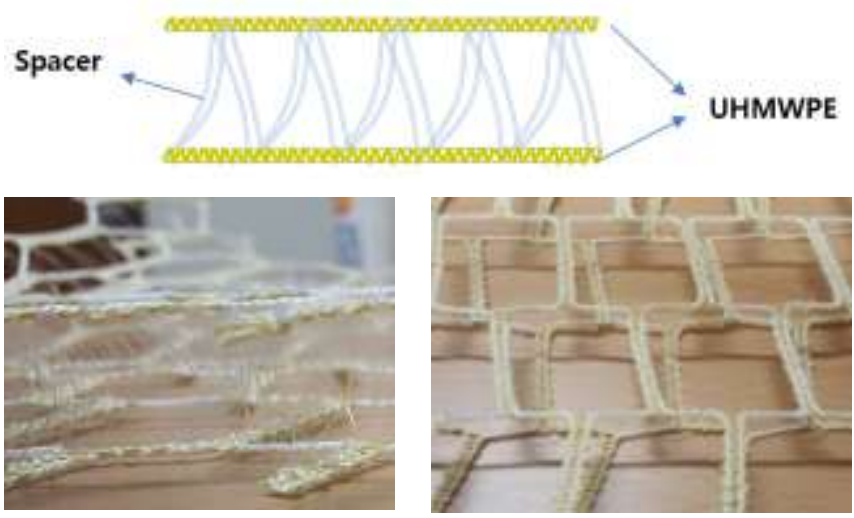

Figure 1. 3D UHMWPE fiber

\section{B. Test Matrix and Setup}

In order to assess the structural performance of RC beams strengthened by 3D UHMWPE fiber, a total of 6 specimens was constructed. The first set of specimens was a normal beam without any retrofit. The second set of specimens was strengthened by 3D UHMWPE textile fabric. As shown in Table II, four were designed to be failed by shear while two were flexural critical beams. The shear span-to-depth $(\mathrm{a} / \mathrm{d})$ ratios of shear and flexural critical beams are 2.5 and 5.0, respectively. As shown in Fig. 2, the section of the test specimens is $150 \times 300 \mathrm{~mm}$ with 2 -D19 Flexural rebar and a D10 stirrup. The typical spacing of the stirrup is either $130 \mathrm{~mm}$ or $200 \mathrm{~mm}$. The concrete strength is expected to be $27 \mathrm{MPa}$ while the yield strength of rebar is expected to be $400 \mathrm{MPa}$.

TABLE II. TEST MATRIX FOR RC BEAMS

\begin{tabular}{|c|c|c|c|c|c|}
\hline $\begin{array}{c}\text { Failure } \\
\text { Mode }\end{array}$ & $\begin{array}{c}\text { Retrofit } \\
\text { Type }\end{array}$ & $\begin{array}{c}\text { Specimen } \\
\text { Name }\end{array}$ & Section & $\begin{array}{c}\text { Leng } \\
\text { th }\end{array}$ & $\begin{array}{c}\text { Stirrup } \\
\text { Spacing }\end{array}$ \\
\hline \multirow{2}{*}{$\begin{array}{c}\text { Shear } \\
\text { Critical } \\
\text { Beam }\end{array}$} & - & NS150-S1 & $150 X 300$ & 2260 & 130 \\
\cline { 2 - 6 } & 3D Fiber & RS150-S2 & $150 X 300$ & 2260 & 200 \\
\cline { 2 - 6 } & RS150-S1 & $150 X 300$ & 2260 & 130 \\
\hline $\begin{array}{c}\text { Flexural } \\
\text { Critical } \\
\text { Beam }\end{array}$ & - & NF150 & $150 X 300$ & 2260 & 200 \\
\cline { 2 - 6 } & 3D Fiber & RF150 & $150 X 300$ & 3540 & 130 \\
\hline
\end{tabular}

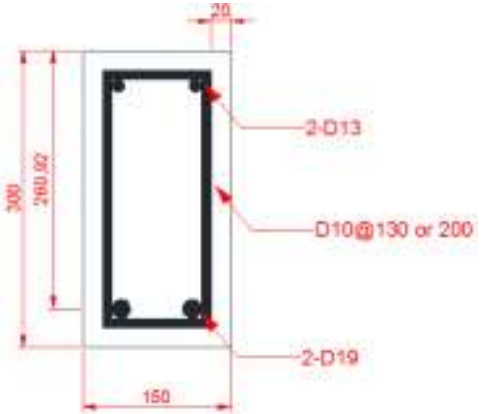

(a) Section

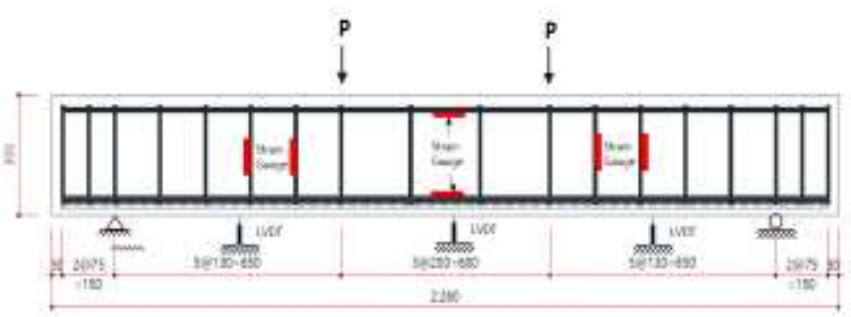

(b) Test setup for shear critical beam (RS150-S1)

Figure 2. Section of specimens and test setup

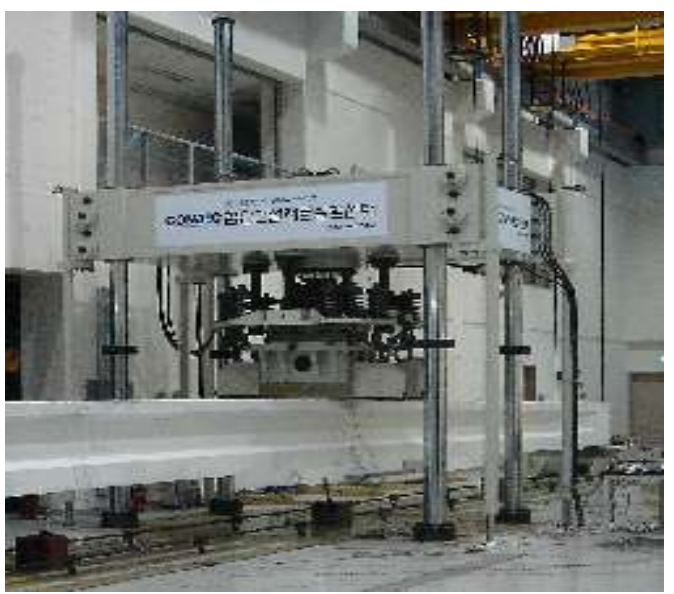

Figure 3. $5 \mathrm{MN}$ static tester

All specimens are constructed and currently being tested. During testing, displacement along the length of the beams is monitored by 3 linear variable displacement transducers (LVDTs), as shown in Fig. 2. Two LVDTs were placed on the one-third of beam length from each support and the last one was located at mid-span. The deformation of the beam was also monitored by strain gauges mounted on reinforcement. The beams were subjected to four-point loading, as shown in Fig. 2. The load was applied to the beam utilizing $5 \mathrm{MN}$ static tester as shown in Fig. 3. The beam was loaded to failure under displacement control at a rate of $1 \mathrm{~mm} / \mathrm{min}$.

\section{Analytical Prediction}

The analytical prediction was performed by using the Response 2000 which is fiber analysis program for RC members employing the Modified Compression Field Theory [11]. As shown in Fig. 4 and Fig. 5, RC beams strengthened by 3D fiber show the higher strength compared to those without the fiber. For the shear critical specimens, the maximum forces of NS150 and RS150 are $52.6 \mathrm{kN}$ and 
Proc. of the Fourth Intl. Conf. Advances in Civil, Structural and Mechanical Engineering- CSM 2016

Copyright ( ) Institute of Research Engineers and Doctors, USA .All rights reserved.

ISBN: 978-1-63248-093-4 doi: 10.15224/ 978-1-63248-093-4-32

$65.3 \mathrm{kN}$, respectively. Thus, maximum force are increased by $24.14 \%$ when the $3 \mathrm{D}$ fiber is used. For the flexural critical specimens, the maximum force of the strengthened specimen also increases by $24.09 \%$ compared to the specimen without any retrofit.

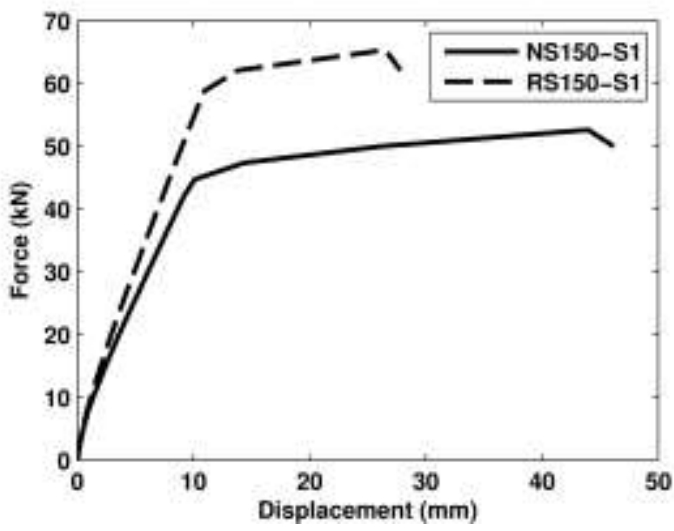

Figure 4. Predicted displacement-force relationship of shear critical beams

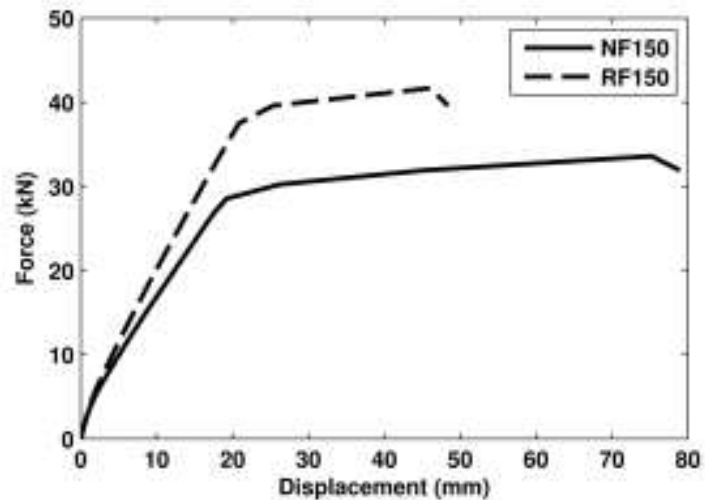

Figure 5. Predicted displacement-force relationship of flexural critical beams

\section{Preliminary Test}

\section{A. Test Specimens}

Before conducting tests with RC beams strengthened by 3D UHMWPE fibers, the conventional concrete cylinder and beam test were conducted in order to evaluate the effect of 3D UHMWPE fiber on the compressive and flexural strengths of concrete.
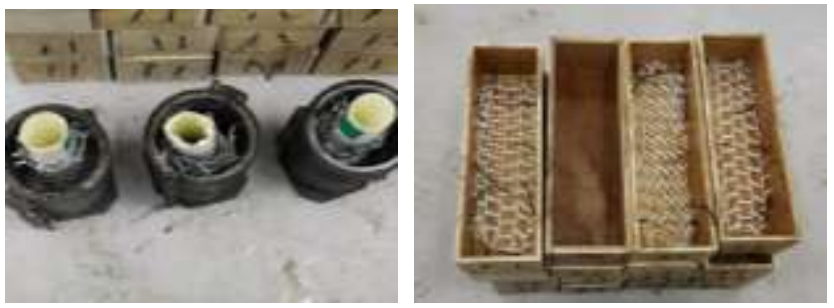

Figure 6. Specimens for the compressive and flexural strengh test of concrete with 3D UHMWPE fiber
A total of nine concrete cylinders with a dimension of $150 \mathrm{~mm} \times 200 \mathrm{~mm}$ was constructed and tested to evaluate the compressive strength of specimens. Three of them are the normal concrete specimens without any fibers while rest of them are strengthened by 3D UHMWPE fiber as shown in Fig. 6. The 3D UHMWPE fiber was placed on near surface of the cylinder mold. Additionally, a total of eight concrete beam with $100 \mathrm{~mm} \times 100 \mathrm{~mm} \times 400 \mathrm{~mm}$ was constructed and tested to assess the flexural strength of concrete with 3D UHMWPE fiber. Two of them are the normal concrete while six of them are strengthened by 3D UHMWPE fiber which are placed at the bottom of specimen as shown in Fig. 6 .

\section{B. Test Results}

As shown in Fig. 7, the compressive strength test with nine specimens were conducted. As detailed in Table III, concrete compressive strength is $31.93 \mathrm{MPa}$, while the average strength of the specimen with $3 \mathrm{D}$ fiber is $40.01 \mathrm{MPa}$. The compressive strength of specimens increases by $25.3 \%$. Thus, test results indicate that 3D UHMWPE fiber can significantly affect the compressive strength of concrete.
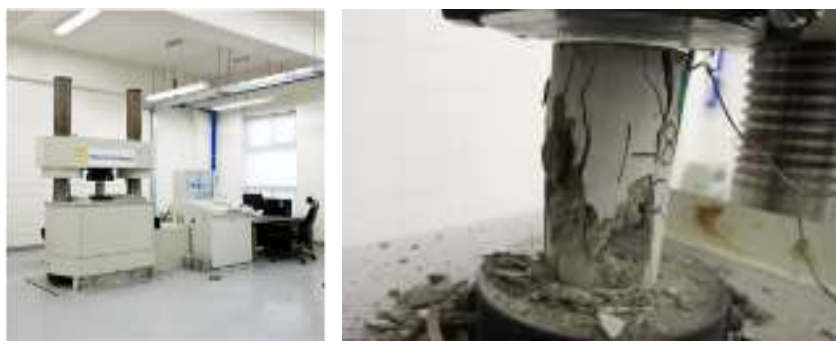

Figure 7. Compressive test of concrete with 3D fiber

TABLE III. COMPRESSIVE STRENGTH OF CONCRETE

\begin{tabular}{|c|c|c|c|c|}
\hline \multirow{2}{*}{ Type } & \multicolumn{3}{|c|}{ Compressive Strength (MPa) } & $\begin{array}{c}\text { Average } \\
\text { (MPa) }\end{array}$ \\
\hline \multirow{2}{*}{ Normal } & 32.15 & 30.57 & 33.08 & 31.93 \\
\hline \multirow{2}{*}{ TRC } & 41.77 & 35.67 & 42.08 & \multirow{2}{*}{40.01} \\
\cline { 2 - 4 } & 38.96 & 42.30 & 39.30 & \\
\hline
\end{tabular}

As described previously, tests for flexural strength of concrete with 3D UHMWPE fiber were conducted as illustrated in Fig. 8. The displacement at mid-span of specimen was measured by using the LVDT.

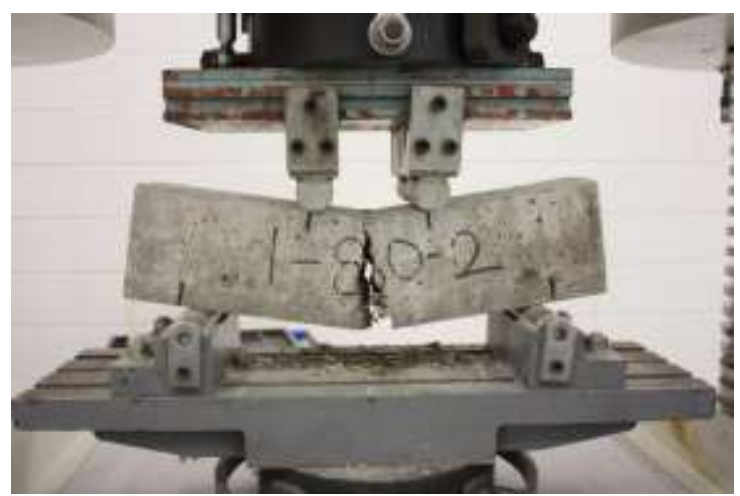

Figure 8. Flexural test of concrete with 3D fiber 
As shown in Fig. 9, 3D UHMWPE fiber affects significantly the performance of concrete beams. The average flexural strength of normal concrete and TRC are 3.89 $\mathrm{MPa}$ and 4.68 $\mathrm{MPa}$, respectively. Thus, the flexural strength of concrete increases by $20.3 \%$ when the 3D UHMWPE fibers are included.

The displacement at the peak load is also notably affected. The displacement of TRC increases by $106.89 \%$ compared to that of normal specimen. After the peak load, the normal concrete specimens were abruptly failed as indicated in Fig. 9. However, the TRCs show the residual strength after peak load as shown in Fig. 9.

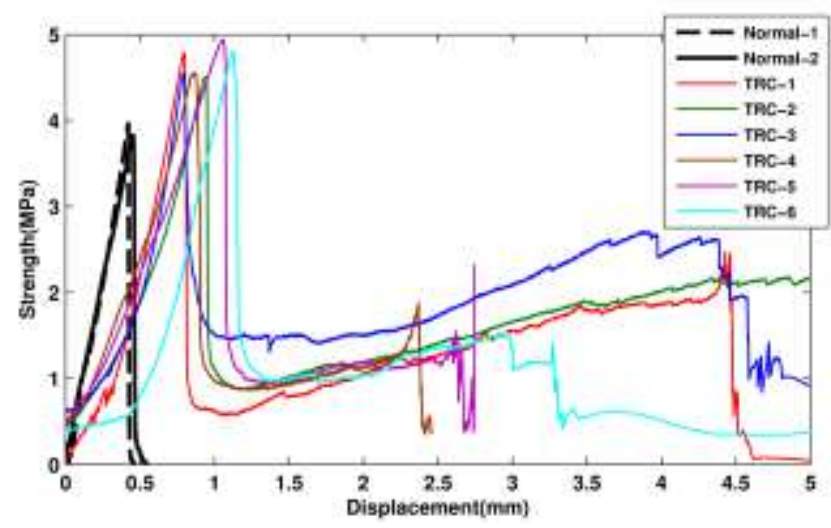

Figure 9. Flexural test result

\section{Conclusion}

In this paper, the structural performance of concrete strengthened by 3D UHMWPE fiber was experimentally evaluated. Also, the ongoing experimental program of investigation on the performance of RC beams strengthened with 3D UHMWPE is also introduced. The most important findings are summarized below.

From the preliminary test, 3D UHMWPE fiber can significantly affect both the compressive and flexural strength of concrete. Both strengths increased by about $20 \%$ when $3 \mathrm{D}$ fiber is included in the specimen. One of the most interesting behaviors is that the specimen strengthened by 3D UHMWPE fiber shows the relatively high residual strength after concrete failure.

Hence, considering observations from these tests described above, it is clearly shown that the retrofitting method using 3D UHMWPE fiber influences the behavior of concrete structure and could dictate the failure mode.

\section{Acknowledgment}

This research was supported by the Ministry of Trade, Industry \& Energy(MOTIE), Korea Institute for Advancement of Technology(KIAT) through the Encouragement Program for The Industries of Economic Cooperation Region under Award No. R0002902.

\section{References}

[1] H. Saadatmanesh, M.R. Ehsani and L. Jin, "Seismic strengthening of circular bridge pier models with fibre composites," ACI Structural Journal, vol. 93(6), pp.639-647, 1996.

[2] H. Saadatmanesh, M.R. Ehsani and L. Jin, "Repair of earthquakedamaged RC columns with FRP wraps", ACI Structural Journal, vol. 94(2), pp.206-215, 1997.

[3] F. Seible, G.A. Hegemier, M.J.N. Priestley and D. Innamorato, "Developments in bridge column jacketing using advaced composites," Proceedings of the National Seismic Conference on Bridges and Highways, San Diego, pp.15, December 1995.

[4] Y. Xiao, G.R. Martin, Z. Yin and R. Ma, "Retrofit design of existing reinforced concrete bridge columns using prefabricated composite jacketing," Proceedings National Seismic Conference on Bridges and Highways, San Diego, pp.14, December 1995.

[5] T. Yamamoto, "FRP strengthening of RC columns for seismic retrofitting," Proceedings of the 10th World Conference on Earthquake Engineering, Madrid, Balkema, vol. 9, pp.5205-5210, 1992.

[6] B. Gao, C. Leung and J. Kim, "Prediction of concrete cover separation failure for RC beams strengthened with CFRP strips," Engineering Structures, vol. 27, pp.177-189, 2005.

[7] E. Amzaleg, A. Peled, S. Janetzko and T. Gries, "Flexural behavior of cement based element reinforced with 3D fabric," VIII International Conference on Fracture Mechanics of Concrete and Concrete Strctures. Toledo, March 2013.

[8] E.A. Sasi and A. Peled, "Three dimensional (3D) fabrics as reinforcements for cement-based composites," Composites Part A: Applied Science and Manufacturing, vol. 74, pp.153-165, April 2015.

[9] M. Tsesarsky, A. Katz, A. Peled and O. Sadot, "Textile reinforced concrete (TRC) shells for strengthening and retrofitting of concrete elements: influence of admixtures," Materials and Structures, vol. 48(1-2), pp.471-484, October 2013

[10] G.J. Parra-Montesinos, S.W. Peterfreund and S. Chao, "Highly damage-tolerant beam-column joints through use of high-performance fiber-reinforced cement composites," ACI Structural Journal, vol. 102(3), pp.487-495, 2005.

[11] E.C. Bentz, "Sectional Analysis of Reinforced Concrete Members", $\mathrm{PhD}$ Thesis, Department of Civil Engineering, University of Toronto, 2000 . 